\title{
Screening of Rosa damascena Mill. landraces for flower yield and essential oil content in cold climates
}

Bayzid Yousefi

Kurdistan Agriculture and Natural Resources Research Center Sanandaj, Kurdistan, Islamic Republic of Iran

\begin{abstract}
In order to evaluate flower yield and essential oil content of Rosa damascena, 49 landraces were studied in a randomized complete block design with three replications in Sanandaj (Iran) during 2004-8. An analysis of variance revealed significant differences $(\mathrm{p} \leq 0.01)$ for the number of flowers per plant, flower and petal weight, flower and petal yield per plant, essential oil ratio and essential oil yield per plant among landraces $(\mathrm{G})$, years (Y) and for landrace $\times$ year (GY). The landraces of FA1, KR2, KR3, FA2, AR1 and YZ2 with 3291.9, 2526.4, 2298.7, 2239.8, 2077.6 and $1978.7 \mathrm{~kg} \mathrm{ha}^{-1}$, respectively, produced the highest flower yield and the landraces of IS3, IS2, KR2, IS4 and FA2 with 413.25, 378.11, 364.31, 315.30 and $296.10 \mathrm{~g} \mathrm{ha}^{-1}$, respectively, produced the highest essential oil among all of the landraces. In accordance to this, cluster analysis also classified high flower and essential oil yield landraces in distinct groups at an $87 \%$ similarity. According to the results, most landraces that originated from temperate, warm temperates and arid regions such as the FA2, YZ2 and Isfahan group of landraces produced higher flower yield and essential oil than those from cool, cool temperate, semi-arid and humid regions. Taking into consideration flower yield and essential oil, the landraces of KR2, YZ2, IS3, IS2 and FA2 with 2526.4, 1978.7, 1659.8, 1663.2 and $2239.8 \mathrm{~kg} \mathrm{ha}^{-1}$ flower yield, respectively, and $364.31,265.31,413.25,378.11$ and $296.10 \mathrm{~g} \mathrm{ha}^{-1}$ essential oil, respectively, produced the highest flower yield and essential oil content among the landraces and are recommended for semi-temperate and cool areas.
\end{abstract}

Key words: essential oil, flower yield, medicinal plants, Rosa damascena Mill.

\section{INTRODUCTION}

Damask rose (Rosa damascena Mill.) is widely cultivated for its essential oil, medicinal properties and ornamental aspects in many areas of the world, e.g. Bulgaria, Turkey, India and Iran (TabaeiAghdaei et al. 2002). The various parts of the Damask rose plant, especially the flowers, are valuable in the medicinal, food and aromatic industries. The fresh flowers of this plant are used in the preparation of jam and dried flowers for edible purposes. Its petals are used in dispelling sorrow, palpitations, insomnia, stomach upset and inflammation. In addition, rose petal syrup has blood purifying, diuretic and chronic nephritis treatment properties (chronic inflammation of the kidneys) (Ody 1995). The extract obtained from the distillation of rose was used to depression treat in the Middle Ages (Chevallier 1996). Rose water and powdered roses are used in Middle Eastern and Eastern cooking. The most popular use is in the flavoring of desserts such as ice cream, jam, rice pudding, cake, yoghurt, etc. The fruits of the rose species are beneficial for human health as they contain important organic and inorganic matters (Kazaz et al. 2009). The seeds of rose hip 
also contain unsaturated and polyunsaturated fatty acids (Szentmihalyi 2002). Rosa damascena fruits contain ascorbic acid, $\alpha$-tocopherol, $\beta$-carotene, and mineral elements such as $\mathrm{Ca}, \mathrm{Fe}, \mathrm{K}, \mathrm{Mn}, \mathrm{Na}$, $\mathrm{P}$ and $\mathrm{Zn}$ (Kazaz et al. 2009). Traditionally, rose oil is used as a remedy for anxiety, depression and for the treatment of stress-related condition 52 and in aromatherapy for the treatment of cardiac diseases (Hongratanaworakit 2009). In addition to its application in aromatic industries, several valuable characteristics of Damask rose oil - such as antiHIV (Mahmood et al. 1996), antibacterial (Basim and Basim 2003) and antioxidant (Achuthan et al. 2003, Ozkan et al. 2004) activities - have been reported recently. Damask rose is the national flower of Iran (Kaffi and Riazi 2002), but the production of flower yield for rose water is the main goal of rose cultivation there and essential oil is considered a sub-product. In order to meet the growing demand of rose oil, there is an urgent need to extend the cultivation of $R$. damascena to a larger area (Probir 2013). Since there are no natural alternatives or artificial rose essential oil, it is one of the most expensive essential oils on world markets (Baydar and Baydar 2004). Many research articles have been written about garden roses, but the roses used for essential oil production have been less widely described in the scientific literature. Considerable variation among Iranian Damask rose populations has been reported for many traits such as flower yield and oil content (Tabaei-Aghdaei et al. 2002, 2005, Rezaei et al. 2003, Jaymand et al. 2004, Babaei et al. 2007, Yousefi et al. 2009a,b). Nirmal and Sushil-Kumar (2002) introduced a new variety of Damask rose named "Rani Saheb" that was a half sib progeny of Damask rose and its biomass and essential oil yield were twice while its morph-physiological characteristics were stable. Therefore, it is possible to achieve genotypes with higher and more stable performance for other areas such as Iran.

Because the production of flowers and essential oil are the main purposes of the cultivation of Damask rose (Rosa damascena Mill.) as an important aromatic and medicinal plant, we should improve these characteristics by various plant breeding methods. Considering this, collecting and evaluating the native rose germplasm from the viewpoints of flower and essential oil yield especially under environmental stress such as cold conditions, drought, etc. is an important research need. Therefore, the present study was carried out to evaluate the flower yield and essential oil content of 49 different Iranian Damask rose landraces to introduce superior ones.

\section{MATERIAL AND METHODS}

This research was performed in the Jalleh research station of the Agriculture and Natural Resources Research Center of the Kurdistan province (Sanandaj - Iran) over the course of five years (2004-8). The research area is located in the semitemperate and cool areas of Iran, at an altitude of $1373.4 \mathrm{~m}$, with a yearly mean optimum temperature of about $16^{\circ} \mathrm{C}$, annual rainfalls and evaporation equal to 462.4 and $1340 \mathrm{~mm}$, respectively, and 2860 total sunny hours. The research materials consisted of 49 Damask rose landraces belonging to all parts of Iran (Tab. 1, Fig. 1). The land preparation and planting holes (with a diameter and depth equal to $1 \times 1 \mathrm{~m}$ ) were conducted in the autumn of 2004. After preparing the holes (soil bed with a mixture of soil, sand and manure) and culture conditions, safe and uniform annual saplings of the landraces were planted in March 2004 using a randomized complete block design (RCBD) with three replications. Plant spacing was $3 \times 3 \mathrm{~m}$ (1111 plants per hectare) and every plot was comprised of three plants. Normal cultural practices were followed as and when necessary. Data concerning the studied traits were collected in the third to the fifth years of the experiment (2006-8) during the appropriate time (early to late June) related to the annual conditions.

Whole flowers of each plant per plot were collected for every replication and landraces were collected daily separately in each year. For the measurement of average flower and petal weight, 10 individual fresh flowers were selected randomly and then weighted both whole and without petals and were recorded for each plant in the plot. After the harvest, the number of flowers per plant was determined and fresh flowers were weighted with and without petals. The flower and petal yield data (mean of three plants in each plot) were recorded and then yield per hectare was calculated. The extraction of essential oil was performed by hydro distillation (HD) and solvent (diethyl ether) for years and landraces separately using fresh flowers. At the end of extraction, the essential oil weight of each genotype was calculated by the weight of the micro tube containing essential oil minus the micro tube weight. The essential oil ratio of each landrace was calculated by dividing its essential oil weight by the initial flower weight $(500 \mathrm{~g})$. The essential oil yield per plant and hectare for each landrace 
Table 1. Origins of Damask rose landraces according to geographical similarities

\begin{tabular}{lccc}
\hline Landraces & Origin site & Province(s) included & Climate* \\
\hline IS1- IS10 & Os1 & Isfahan & T, A \\
EA1, WA1, AR1 & Os2 & East and west Azerbaijan, Ardabil & CT, SA \\
IL1, KS1 & Os3 & Kermanshah, Illam & CT, SA \\
TH1, AK1 & Os4 & Tehran, Markazi & CT, T, SA \\
CM1, KB1, LO1 & Os5 & Chaharmahall, Kohkilloyah, Lorestan & T, SA \\
KO2 & Os6 & Razavi Khorasan & W, A \\
KZ1, HO1, BC1 & Os7 & Khuzestan, Hormozgan, Sistan & CT, SA \\
ZA1, QZ1 & Os8 & Zanjan, Qazvin & WT, A \\
SM1, SM2, QM1 & Os9 & Semnan, Qom & T, SA, A \\
FA1, FA2, KM1 & Os10 & Fars, Kerman & C, SA \\
HA1, KR1-KR12 & Os11 & Kurdistan, Hamedan & T, H \\
GU1, GL1 & Os12 & Guilan, Gulestan & WT, A \\
YZ1, YZ2 & Os13 & Yazd & \\
\hline
\end{tabular}

*T: Temperate, C: Cool, W: Warm, A: Arid, SA: Semi-arid, H: Humid

Yearly mean temperatures in warm, temperate and cool climates are $15-25^{\circ} \mathrm{C}, 10-15^{\circ} \mathrm{C}$ and $0-5^{\circ} \mathrm{C}$, respectively. Yearly mean rainfalls in semi-humid, semi-arid and arid climates are 600-1400, 300-600 and 100-300 mm, respectively.

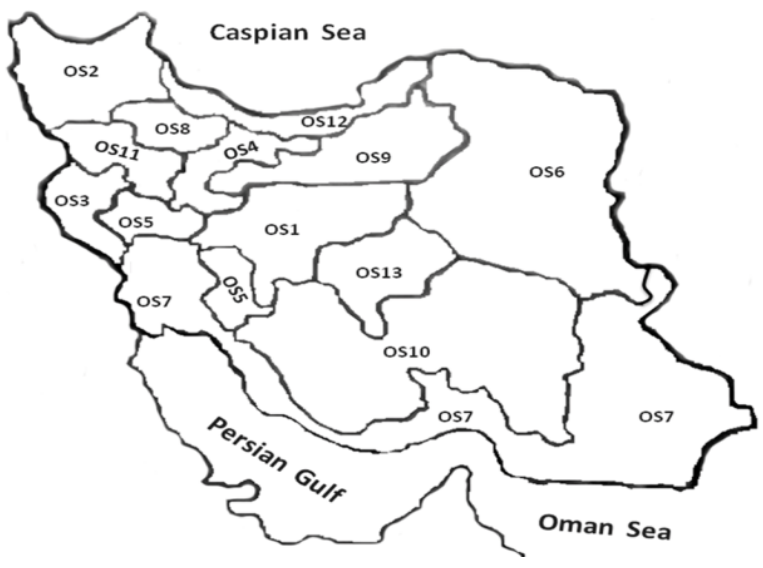

Figure 1. The origin sites of Damask rose landraces (Os1-Os13) on the map of Iran (Yousefi et al. 2009b)

were calculated proportionally to its flower yield per plant (essential oil ratio $\times$ flower yield per plant) and hectare (essential oil yield per plant $\times$ flower yield per hectare) annually.

An analysis of variance as a split plot in times (years) with a basic statistical design of a randomized complete block design (RCBD) was used to estimate the mean square of landraces, years and landrace $x$ years interactions, while Duncan's multiple ranges test was also used for comparisons of the means. Cluster analysis (using an agglomerative hierarchical method with standardised variables by subtracting the means and dividing by the standard deviation and dendrogram using the average linkage method and squared Euclidean distance) were performed for the grouping of landraces based on the studied traits.

\section{RESULTS}

The analysis of variance revealed significant differences $(p \leq 0.01)$ in all of the studied traits, including the number of flowers per plant (FN/P), average fresh flower weight (FFW), flower yield per plant (FY/P), average fresh petal weight (FPW), petal yield per plant (PY/P), essential oil ratio (EOR) and essential oil per plant $(\mathrm{EO} / \mathrm{P})$ among landraces $(\mathrm{G})$, years $(\mathrm{Y})$ and for landrace $\times$ year (GY) (Tab. 2). As it is shown in Table 2, the means of FN/P, FFW, FY/P, FPW, PY/P, PY/P, EOR and $\mathrm{EO} / \mathrm{P}$ were $543.57,2.38 \mathrm{~g}, 1214.9 \mathrm{~g}, 1.85 \mathrm{~g}$, $943.47 \mathrm{~g}, 1.06 \times 10^{-4}(0.01 \%)$ and $0.13 \mathrm{~g}$, respectively. The means of EOR in 2006 and $2008(0.013 \%$ and $0.01 \%)$ were more than in $2007(0.009 \%)$ and also the mean of EO/P in 2008 with $0.20 \mathrm{~g} \mathrm{plant}^{-1}(219.20$ $\mathrm{g} \mathrm{ha}^{-1}$ ) was more than in the previous years (Tab. 3).

According to the landrace means (Tab. 4), the landraces of FA1, KR2, KR3, FA2, AR1 and YZ2 with 2963.1, 2274.5, 2069.4, 2016.2, 1870.2 and $1781.3 \mathrm{~g} \mathrm{plant}^{-1}$, respectively, (with 3291.9, 2526.4, 2298.7, 2239.8, 2077.6 and 1978.7 $\mathrm{kg} \mathrm{ha}^{-1}$, respectively) produced the highest flower yield, while the landraces of LO1, GL1, KR12, KR7 and KR6 with 225, 237.4, 346.2, 451.9 and 465.2 g plant $^{-1}$, respectively, (with 249.98, 263.75, 384.63, 502.06 and $516.84 \mathrm{~kg} \mathrm{ha}^{-1}$, respectively) produced the lowest flower yield among the studied landraces.

The landraces of IS3, IS2, IS4, IS8 and TH1 with $2.10 \times 10^{-4}(0.021 \%), 2.06 \times 10^{-4}(0.021 \%), 1.79$ $\times 10^{-4}(0.018 \%), 1.74 \times 10^{-4}(0.017 \%)$ and $1.62 \times 10^{-4}$ $(0.016 \%)$, respectively, showed the highest essential 
Table 2. Analysis of variance (split plot in time) of the studied traits of 49 Damask rose landraces

\begin{tabular}{|c|c|c|c|c|c|c|c|c|}
\hline $\begin{array}{l}\text { Sources of variation } \\
\text { (SV) }\end{array}$ & $\begin{array}{l}\text { Degree } \\
\text { of } \\
\text { freedom } \\
\text { (DF) }\end{array}$ & $\begin{array}{c}\text { Number of } \\
\text { flowers per } \\
\text { plant } \\
(\mathrm{FN} / \mathrm{P})\end{array}$ & $\begin{array}{c}\text { Average } \\
\text { fresh flower } \\
\text { weight } \\
\text { (FFW) }\end{array}$ & $\begin{array}{c}\text { Flower yield } \\
\text { per plant } \\
\text { mean } \\
(\mathrm{FY} / \mathrm{P})\end{array}$ & $\begin{array}{l}\text { Average } \\
\text { fresh petal } \\
\text { weight } \\
\text { (FPW) }\end{array}$ & $\begin{array}{c}\text { Petal yield } \\
\text { per plant } \\
\text { mean } \\
(\mathrm{PY} / \mathrm{P})\end{array}$ & $\begin{array}{l}\text { Essential } \\
\text { oil ratio } \\
(\mathrm{EOR})^{* * *}\end{array}$ & $\begin{array}{c}\text { Essential } \\
\text { oil per } \\
\text { plant } \\
(\mathrm{EO} / \mathrm{P})\end{array}$ \\
\hline Block (R) & 2 & $4694075^{* *}$ & $0.46^{\mathrm{ns}}$ & $16941773^{* *}$ & $0.27^{* *}$ & $17788515^{* *}$ & $0.016^{* *}$ & $0.05^{\text {ns }}$ \\
\hline Landraces (G) & 48 & $1615536^{* *}$ & $6.21^{* *}$ & $7259516^{* *}$ & $3.01^{* *}$ & $4934912^{* *}$ & $0.004^{* *}$ & $0.14^{* *}$ \\
\hline Error (Ea) & 96 & 449232 & 0.50 & 2359724 & 0.02 & 1526155 & 0.001 & 0.02 \\
\hline Year (Y) & 2 & $106133976^{* *}$ & $11.24^{* *}$ & $456914193^{* *}$ & $15.40^{* *}$ & $259336468^{* *}$ & - & $5.50^{* *}$ \\
\hline Year × Block $(\mathrm{RY})$ & 4 & $1457685^{* *}$ & $0.15^{\mathrm{ns}}$ & $5056305^{* *}$ & $0.02^{\mathrm{ns}}$ & $5679920^{* *}$ & - & $0.06^{* *}$ \\
\hline Year $\times$ Landrace $(\mathrm{GY})$ & 96 & $638259^{* *}$ & $0.52^{* *}$ & $2808702^{* *}$ & $0.23^{* *}$ & $2435259^{* *}$ & - & $0.08^{* *}$ \\
\hline Error $(\mathrm{Eb})$ & 192 & 68065 & 0.15 & 434235 & 0.02 & 281336 & - & 0.005 \\
\hline
\end{tabular}

** and ns denote significant at $1 \%$ and nonsignificant, respectively.

*** Analysis of variance based on a randomized complete block design (Years as blocks)

Table 3. Mean comparisons of years of studied traits among 49 Damask rose landraces by Duncan's test $(\mathrm{p} \leq 0.01)$

\begin{tabular}{lccccccc}
\hline Year & $\begin{array}{c}\text { Number of } \\
\text { flowers per } \\
\text { plant }(\mathrm{N})\end{array}$ & $\begin{array}{c}\text { Average fresh } \\
\text { flower weight } \\
(\mathrm{g})\end{array}$ & $\begin{array}{c}\text { Flower yield } \\
\text { per plant } \\
(\mathrm{g})\end{array}$ & $\begin{array}{c}\text { Average fresh } \\
\text { petal weight } \\
(\mathrm{g})\end{array}$ & $\begin{array}{c}\text { Petal yield } \\
\text { per plant } \\
(\mathrm{PY} / \mathrm{P})\end{array}$ & $\begin{array}{c}\text { Essential } \\
\text { oil } \\
\text { ratio }\end{array}$ & $\begin{array}{c}\text { Essential } \\
\text { oil per } \\
\text { plant }(\mathrm{g})\end{array}$ \\
\hline 2006 & $131.31 \mathrm{c}$ & $2.37 \mathrm{~b}$ & $316.34 \mathrm{c}$ & $1.85 \mathrm{~b}$ & $243.58 \mathrm{c}$ & $1.30 \times 10^{-4}$ & $0.06 \mathrm{~b}$ \\
2007 & $383.23 \mathrm{~b}$ & $2.54 \mathrm{a}$ & $944.90 \mathrm{~b}$ & $1.98 \mathrm{a}$ & $732.35 \mathrm{~b}$ & $9.06 \times 10^{-5}$ & $0.07 \mathrm{~b}$ \\
2008 & $1111.19 \mathrm{a}$ & $2.21 \mathrm{c}$ & $2375.96 \mathrm{a}$ & $1.71 \mathrm{c}$ & $1855.01 \mathrm{a}$ & $1.04 \times 10^{-4}$ & $0.20 \mathrm{a}$ \\
\hline
\end{tabular}

The means with different letters show significant differences at a 0.01 probability

oil ratio while FA1, LO1, KR3, QZ1 and KR4 with $2.70 \times 10^{-5}, 2.80 \times 10^{-5}, 5.40 \times 10^{-5}, 5.40 \times 10^{-5}$ and $6.1 \times 10^{-5}$, respectively, showed the lowest essential oil ratio among the studied landraces (Tab. 4). In addition, the landraces of IS3, IS2, KR2, IS4 and FA2 with $0.37,0.34,0.33,0.28$ and 0.27 g plant $^{-1}$, respectively, (with 413.25, 378.11, 364.31, 315.30 and $296.10 \mathrm{~g} \mathrm{ha}^{-1}$, respectively) produced the highest essential oil content while the landraces of LO1, GL1, KR1, KR8 and KR12 with 0.01, 0.03, 0.03,
0.04 and $0.04 \mathrm{~g} \mathrm{plant}^{-1}$, respectively, (with 7.99,

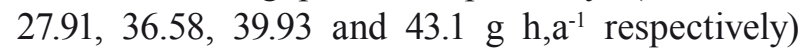
produced the lowest among the studied landraces (Tab. 4 and Fig. 2). Among the first 16 superior landraces for essential oil and flower yield, six of them (IS3, IS2, IS4, IS8, IS6 and IS5 for essential oil and IS7, IS9, IS2, IS3, IS5 and IS1 for flower yield) were of Isfahan origin that wholly originated in the Kashan area. The Isfahan group of landraces produced higher flowers per plant, flower and

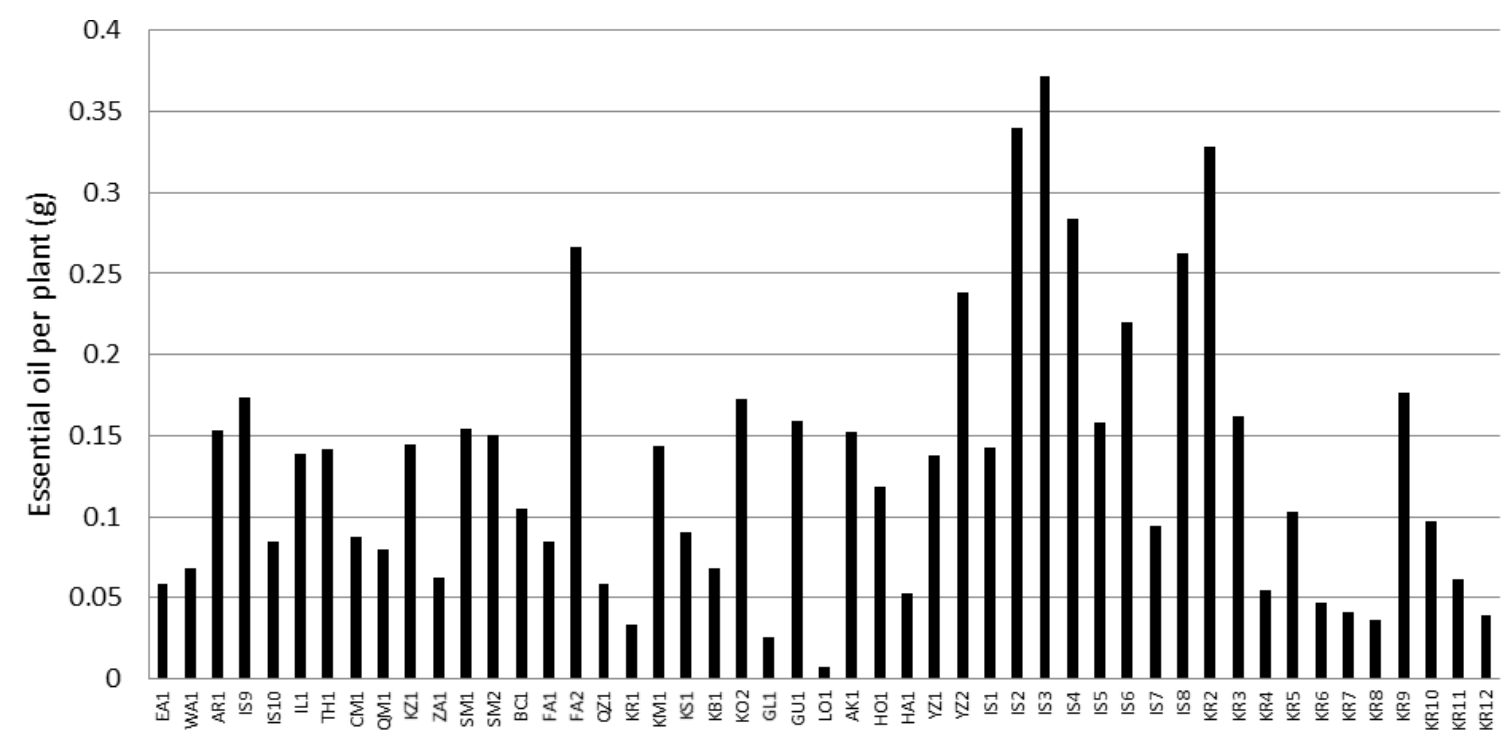

Figure 2. Average content of essential oil per plant of 49 Damask rose landraces 


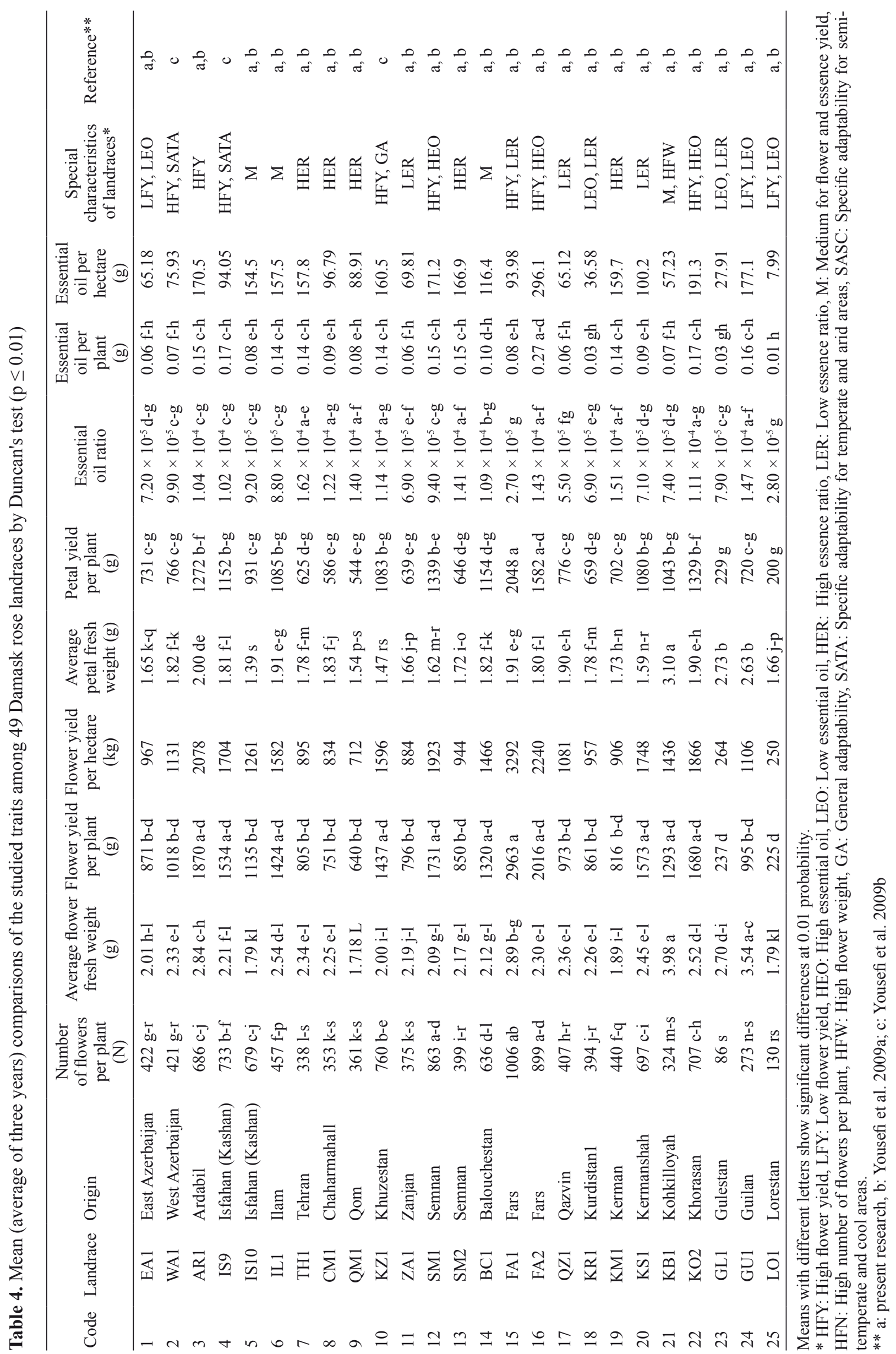




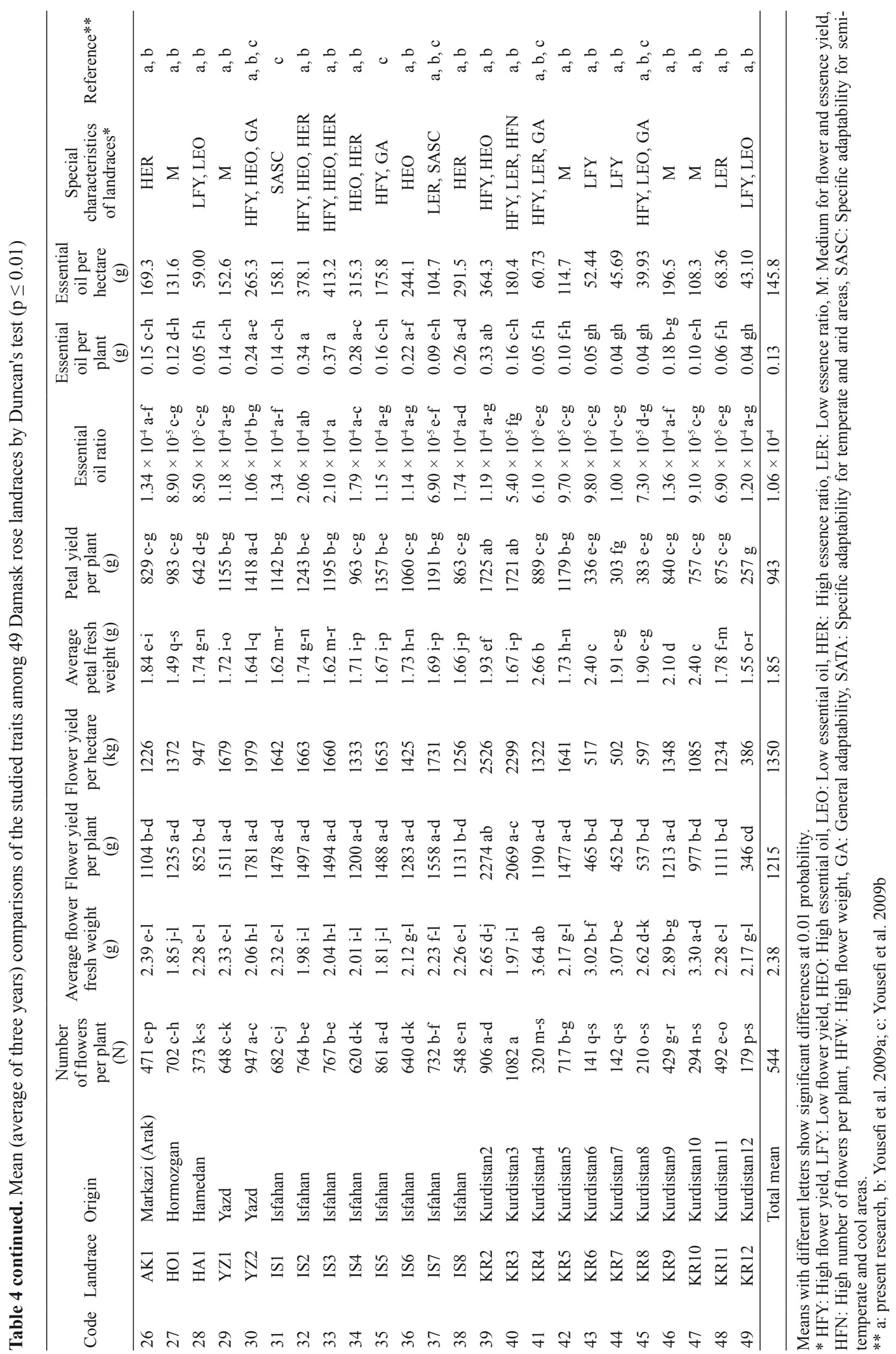




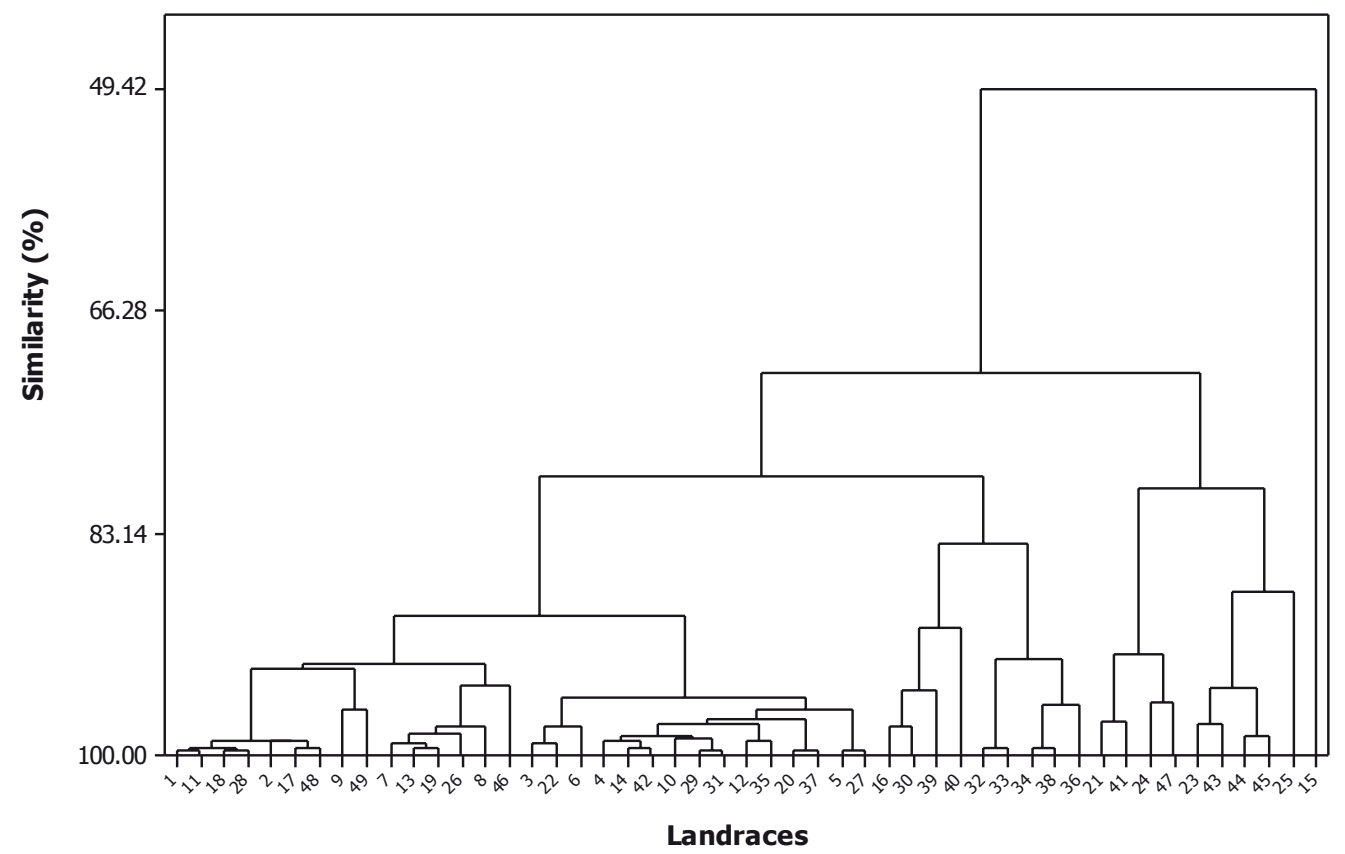

Figure 3. Dendrogram of the cluster analysis of 49 Damask rose landraces based on the studied traits

petal yield, essential oil ratio and also essential oil content than the mean of the studied landraces, while only KR2 and KR3 produced higher flower yield and essential oil content among the Kurdistan group of landraces (Tab. 4 and Fig. 2).

Based on the results of the cluster analysis, 49 landraces of Rosa damascena were classified into six distinct groups at $97.8 \%$ similarity (Fig. 3). The landrace of FA1 with the highest flower yield (3291.9 $\mathrm{kg} \mathrm{ha}^{-1}$ ) was located in the sixth group; the landraces of GL1, KR6, KR7, KR8 and LO1 with the least flower yield mean (425.9 $\left.\mathrm{kg} \mathrm{ha}^{-1}\right)$ and essential oil mean $\left(34.8 \mathrm{~g} \mathrm{ha}^{-1}\right)$ were located in the fifth group; the landraces of KB1, KR4, GU1 and KR10 had low flower and essential oil yield and were in the fourth group; the landraces of IS2, IS3, IS4, IS6 and IS8 had the highest essential oil mean $\left(328.5 \mathrm{~g} \mathrm{ha}^{-1}\right)$ and were in the third group; the landraces of FA2, YZ2, KR2 and KR3 with 2260.9 $\mathrm{kg} \mathrm{ha}^{-1}$ as high flower yield landraces were in the second group; finally, other landraces with 1313.1 $\mathrm{kg} \mathrm{ha}^{-1}$ flower yield mean and $122.42 \mathrm{~g} \mathrm{ha}^{-1}$ essential oil mean were located in the first group.

\section{DISCUSSION}

The main objective of Damask rose cultivation in many countries such as Bulgaria, Turkey and France is the extraction of its flower essential oil (Babu et al. 2002). However, in Iran it is mainly for the production of flowers and rose water, although attention to essential oil is increasing recently day to day and essential oil can be an important source of export revenue for the country (TabaeiAghdaei 2002). Therefore, attention to the quantity and quality of essential oil and flower yield can be considered important objectives for improving this species.

In this study, the analysis of variance revealed significant differences $(\mathrm{p} \leq 0.01)$ for flower yield and its major components and also essential oil among landraces $(\mathrm{G})$, years $(\mathrm{Y})$ and for landrace $\times$ year (GY). The existence of genetic variation is the primary base for breeding programs; therefore, selection for these traits could be possible. In accordance with these results, other Iranian researchers $^{1}$ (Tabaei-Aghdaei et al. 2002, 2005, Rezaei et al. 2003, Jaymand et al. 2004, Babaei et al. 2007, Yousefi et al. 2009a,b) also found significant mean squares among landraces for flower yield and its components. The significant landrace $\times$ year (GY) interactions indicate that flower yield and its components are highly influenced by the changes in times (years).

The essential oil ratio, essential oil yield per plant and hectare in 2008 were more than in 2007. Compared to 2007, the year 2008 was very dry in the Kurdistan province and other areas of Iran. According to this and other results (Yousefi et al. 2009a), it can be inferred that wet conditions increase vegetative and generative traits (e.g. plant height,

\footnotetext{
${ }^{1}$ The number of evaluated landraces in their studies (with the exeption of Yousefi et al. 2009a, b) was about 10-20 landraces and fewer than those in the present study.
} 
flower number, weight and yield) but decrease the quantity of essential oil ratio. Flower and essential oil yield are complex traits with several genetic and environmental components that in a perennial plant such as the Damask rose can be related to the age of plant; the flower and essential oil yield of a one-year-old plant is less than that of two- or threeyear-old ones. It seems that in perennial plants, the effect of age is pooled with the effect of the year. In contrast, some characteristics, e.g. the essential oil ratio of a distinct genotype, can be relatively free from age and its effects. A complementary study of age effects on the flower and essential oil yield can provide a clear answer to this.

Based on the results, the landraces of FA1, KR2, KR3, FA2, AR1 and YZ2 with 2963.1, 2274.5, 2069.4, 2016.2, 1870.2, 1781.3 g plant $^{-1}$, respectively (3291.9, 2526.4, 2298.7, 2239.8, 2077.6 and 1978.7 $\mathrm{kg} \mathrm{ha}^{-1}$, respectively), produced the highest flower yield among the studied landraces. Therefore, the landraces of IS3, IS2, IS4, IS8 and TH1 with $2.10 \times 10^{-4}(0.021 \%), 2.06 \times 10^{-4}(0.021 \%), 1.79 \times$ $10^{-4}(0.018 \%), 1.74 \times 10^{-4}(0.017 \%)$ and $1.62 \times 10^{-4}$ $(0.016 \%)$, respectively, showed the highest essential oil ratio among the studied landraces. In addition, the landraces of IS3, IS2, KR2, IS4 and FA2 with $0.37,0.34,0.33,0.28$ and 0.27 g plant $^{-1}$, respectively (with 413.25, 378.11, 364.31, 315.30 and 296.10 $\mathrm{g} \mathrm{ha}^{-1}$, respectively), produced the highest essential oil content per plant and hectare among the studied landraces. In accordance to this, cluster analysis classified the landraces into six distinct groups at $87 \%$ similarity. The landrace of FA1 with the highest flower yield was located in the sixth and the fourth highest flower yield landraces of KR2, KR3, FA2 and YZ2 were in the second and also the fifth highest essential oil content of the Isfahan group (IS2, IS3, IS4, IS6 and IS8) were located in the third group. Although there were varying origin sites, climates and ecological conditions in both the high and low flower yield and essential oil content landraces groups, most of the Damask rose landraces belonging to temperate, warm temperate and arid regions such as FA2, YZ2 and the Isfahan group of landraces produced higher flower yield and essential oil than those originating from cool, cool temperate, semi-arid and humid regions such as GL1, LO1, GU1, KR6, KR7, KR8, KR12, ZA1, QZ1, TH1, HA1 and EA1. Among the first 16 superior landraces for essential oil and flower yield, six of them (IS3, IS2, IS4, IS8, IS6 and IS5 for essential oil and IS7, IS9, IS2, IS3, IS5 and IS1 for flower yield ) were of Isfahan origin, which wholly originated from the Kashan area.

Kashan farmers have a long history of experience in the cultivation and production of Damask roses and rose water in Iran. This result suggests that the effective role of selection has been accomplished by traditional farmers either arbitrarily or randomized for flower yield improvement. The Isfahan group of landraces produced higher flowers per plant, flower yield, essential oil ratio and yield and heavier petals than other landraces, while only KR2 and KR3 produced higher flower yield and essential oil content among the Kurdistan group of landraces. The average essential oil ratio in the present study $(0.01 \%)$ was less than in previous findings, e.g. Baydar and Baydar (2004) in Turkey $(0.03 \%)$ and Misra et al. (2002) in India (0.05\%). This can be due to several causes: 1 . We evaluated many local, often unknown genotypes belonging to almost all parts and ecological conditions of Iran; 2. As mentioned earlier, the main purpose of rose cultivation in Iran, especially in Kashan (as a source of rose and rose water in Iran), has been the production of flowers and rose water, and even some researchers agree that Iran is the main source of Damask rose and rose water in the world (Chevallier 1996); thus, the main attention in arbitrarily or randomized selections has been on the flower yield instead of essential oil content, therefore the quantity of essential oil of Iranian Damask rose landraces has not found a considerable genetic improvement (Yousefi et al. 2009a, b) and 3. The cold conditions of the present research location.

\section{CONCLUSIONS AND RECOMMENDATIONS}

In conclusion, based on the results of the present study, the essential oil content of Iranian Damask rose landraces is low because of long term selection for flower yield and no considerable attention to oil content. We can conclude that cold and wet conditions decrease the oil content of Damask rose. In addition, the landraces of FA1, KR2, KR3, FA2 and AR1 with 3291.9, 2526.4, 2298.7, 2239.8 and $2077.6 \mathrm{~kg} \mathrm{ha}^{-1}$, respectively, produced the highest flower yield and the landraces of IS3, IS2, KR2, IS4 and FA2 with 413.25, 378.11, 364.31, 315.30 and $296.10 \mathrm{~g} \mathrm{ha}^{-1}$, respectively, produced the highest essential oil among the studied landraces. In accordance to this, cluster analysis also classified high flower and essential oil yield landraces in distinct groups at $87 \%$ similarity. According to the results, most landraces that originated from 
temperate, warm temperate and arid regions such as the FA2, YZ2 and Isfahan group of landraces produced higher flower yields and essential oil than those from cool, cool temperate, semi-arid and humid regions. Due to the high value of rose essential oil, it should be considered in addition to the production of flowers and rose water in Iran. In order to do this, we can improve the flower and essential oil of Damask roses by simultaneous selection and hybridisation in a breeding program using superior landraces such as the KR2, FA2, YZ2 (with high general adaptation based on Yousefi et al. 2009b) and Isfahan group of landraces. Taking into consideration flower yield and essential oil simultaneously, the landraces of KR2, YZ2, IS3, IS2 and FA2 with 2526.4, 1978.7, 1659.8, 1663.2 and $2239.8 \mathrm{~kg} \mathrm{ha}^{-1}$ flower yield, respectively, and 364.31 , 265.31, 413.25, 378.11 and $296.10 \mathrm{~g} \mathrm{ha}^{-1}$ essential oil, respectively, were the superior landraces among the studied landraces and can be recommended as ones with high flower yield and essential oil content for semi-temperate and cool areas such as Sanandaj (Iran).

\section{FUNDING}

This work was supported by the Agricultural and Natural Resources Research Centers of Kurdistan Province (Iran). The author is grateful to Firouz Mardani, Yacob Karegar and the field staff of the Agricultural and Natural Resources Research Centers of Kurdistan Province for their assistance in data collection and maintaining the field trial.

\section{REFERENCES}

Achuthan C.R., Babu B.H., Padikkala J., 2003. Antioxidant and hepatoprotective effects of Rosa damascena. Pharm. Biol. 41: 357-361.

Babaei A., Tabaei-Aghdaei S.R., Khosh-Khui M., Omidbaigi R., Naghavi M.R., Esselink G.D., SMulders M.J.M., 2007. Microsatellite analysis of Damask rose (Rosa damascena Mill.) accessions from various regions in Iran reveals multiple genotypes. BMC-Plant Biol. 7:12, doi:10.1186/14712229-7-12.

Babu K.G.D., Bikramn S., Joshi V.P., 2002. Essential oil composition of Damask rose (Rosa damascena Mill.) distilled under different pressures and temperatures. Flavor Frag. J. 17: 136-140.

Basim E., BAsim H., 2003. Antibacterial activity of Rosa damascena essential oil. Fitoterapia 74: 394-396.

BAYDAR H., BAYDAR, N.G., 2004. The effects of harvest date, fermentation duration and Tween 20 treatment on essential oil content and composition of industrial oil rose (Rosa damascena Mill.). Ind. Crop Prod. 21: 251-255.

Chevallier A., 1996. The Encyclopedia of Medicinal Plants. Dorling Kindersely, London.

Hongratanaworakit T., 2009. Relaxing effect of rose oil on humans. Nat. Prod. Comm. 4: 291-296.

Jaymand K., Rezaei M.B., Tabaei-Aghdaei S.R., BARAZANDEH M.M., 2004. Evaluation of rose essential oil of different areas of Isfahan province. Pajoohesh \& Sazandagi 65: 86-91.

KAFFI M., RiAZI Y., 2002. Cultivation of Rosa damascena Mill. and rose water production. Ministry of Agricultural-Jihad pub. Tehran, Iran.

Kazaz S., Erbas S., Baydar H., 2009. The effects of storage temperature and duration on essential oil content and composition oil Rose (Rosa damascena Mill.). Turk. J. Field Crops 14(2): 89-96.

Mahmood N.S., Piacente C., Pizza A., Bueke A., Khan I., HaY A.J., 1996. The anti- HIV activity and mechanisms of action of pure compounds isolated from Rosa damascena. Biochem. Biophys. Res. Commun. 229: 73-79.

Misra A., Sharma S., Singh A., Patra N.K., 2002. Influence of topographical and edaphic factors on Rose. II. Flowering quality and quantity. Commun. Soil Sci. Plant Anal. 33: 15-18.

Ody P., 1995. The Herb Society's Complete Medicine Herbal. Dorling Kindersley, London.

Ozkan G., SAgdic O., Baydar N.G., Baydar H., 2004. Antioxidant and anti-bacterial activities of Rosa damascena flower extracts. Food Sci. Technol. Int. 10: 277-281.

Nirmal K., Sushil-Kumar P., 2002. High yielding stable plant of Rosa damascena, called Ranisahiba. Council of Scientific and Industrial Research, India.

Probir K.P., 2013. Evaluation, genetic diversity, recent development of distillation method, challenges and opportunities of Rosa damascena: a review. J. Essent. Oil Bear. Plants 16(1): 1-10.

Rezaei M.B., Jaymand K., Tabaei-Aghdaei S.R., BaraZandeh M.M., Meshri-Zadeh S., 2003. Study of essential oil quantity and quality of Damask rose (Rosa damascena Mill.) of central and North West region of Iran. Iranian Med. Aromat. Plant Res. J. 19(4): 339-348.

Szentmihalyi K., Vinkler P., Lakatos B., Illes V., Then M., 2002. Rose hip (Rosa canina L.) oil obtained from waste hip seeds by different extraction methods. Bioresource Technol. 82: 195-201.

Tabaei-Aghdaei S.R., Rezaei M.B., Jaymand K., 2002. Evaluation of variation of flower yield in the Damask rose (Rosa damascena Mill.) genotypes of Kashan (Iran). Iranian J. Forest Rangeland Plants Genet. Breed. 9: 99-111.

Tabaei-Aghdaei S.R., Farhangian S., JaAfari A.A., RezAeI M.B., 2005. Study in variation of Damask rose (Rosa damascena Mill.) collected from 6 central 
provinces of Iran. Iranian Med. Aromat. Plant Res. J. 21(2): 227-239.

Yousefi B., Tabaei-Aghdaei S.R., Assareh M.H., 2009a. Evaluation of genetic variation and correlation of morphological and phonological characteristics and their effects on flower yield of Rosa damascena Mill. accessions in Kurdistan. Final Report of Research Institute of Forest and Rangelands (RIFR), No: 5064.
Yousef, B., Tabaei-Aghdaei S.R., Dadvish F., Assareh M.H., 2009b. Flower yield performance and stability of various Rosa damascena Mill. landraces under different ecological conditions. Sci. Hort. 121: 333339.

Received November 17, 2015; accepted February 8, 2016 